\title{
Stimulation of metamorphosis in an estuarine crab, Chasmagnathus granulata (Dana, 1851): temporal window of cue receptivity
}

\author{
P. Gebauer ${ }^{\mathrm{a}}$, K. Paschke ${ }^{\mathrm{a}}$, K. Anger ${ }^{\mathrm{b}, *}$ \\ ${ }^{\text {a }}$ Facultad de Pesquerías y Oceanografia, Universidad Austral de Chile, Casilla Puerto Montt, 1327, Chile \\ ${ }^{\mathrm{b}}$ Biologische Anstalt Helgoland, Stiftung Alfred-Wegener-Institut für Polar-und Meeresforschung, \\ 27498 Helgoland, Germany
}

Received 28 January 2004; received in revised form 4 April 2004; accepted 26 April 2004

\begin{abstract}
The larvae of most benthic marine invertebrate species must develop for a minimum of time in the plankton before they become competent for settlement and metamorphosis in response to stimulating external cues. In an experimental laboratory study, we identified the temporal window of cue receptivity within the moulting cycle of the megalopa stage of an estuarine crab, Chasmagnathus granulata Dana. This species shows an export strategy including an early larval transport to coastal marine waters where zoeal development takes place, followed by the return of the megalopa stage to brackish habitats where the adults live. In two series of experiments (A, B), megalopae were exposed for differential periods to a combination of metamorphosis-stimulating cues which had previously been found effective (seawater conditioned with adult odor and presence of mud). In experimental series A, these cues were added on successively later days of the moulting cycle, while series B comprised treatments in which the cues were provided from the first day (postmoult) and removed on successively later days of the moulting cycle. Each series of experiments was repeated with larvae originating from two different females (F1, F2). The average development time of megalopae kept continuously in the presence of cues (control experiments, $\mathrm{C} 1$ ) ranged in the two hatches from 9.3 to 9.6 days. In the inverse controls where no cue was added at any time (C2), megalopal development to metamorphosis took on average 11.2-12.0 days. In series A, development duration in treatments with exposure to the cues commencing within 3-4 days after moulting was not significantly different from that in the permanently exposed $\mathrm{C} 1$ controls. Later beginning of the exposure, by contrast, had no stimulating effect (significant delay compared to $\mathrm{C} 1$, no significant difference from unexposed control, C2). In series B, no significant differences in development time were observed between the $\mathrm{C} 1$ controls and treatments with an initial exposure for a minimum of 4 or 6 days of the
\end{abstract}

\footnotetext{
* Corresponding author. Fax: +49-4725-819-369.

E-mail address: kanger@awi-bremerhaven.de (K. Anger).
} 
moulting cycle (F1, F2, respectively). Shorter initial periods of exposure had no metamorphosisstimulating effects (no significant difference from C2). In conclusion, our results from both experiments suggest that the megalopa stage of $C$. granulata is most receptive of stimulating cues during a period lasting from ca. one third to one half of the moulting cycle, which coincides with the transition between stages $\mathrm{C}$ (intermoult) and $\mathrm{D}_{0}$ (early premoult) of Drach's classification system. This suggests an interaction of extrinsic stimulating cues with intrinsic (hormonal) factors involved in the control of the moulting cycle.

(C) 2004 Elsevier B.V. All rights reserved.

Keywords: Brachyura; Larvae; Megalopa; Settlement; Chemical cues; Moulting cycle

\section{Introduction}

Planktonic larvae are the principal agents of dispersal in the life cycles of most benthic marine invertebrates (Thorson, 1950). During the larval period, there is initially a precompetent phase in which the larvae are morphologically and/or physiologically incapable of settling and passing through metamorphosis. This is followed by a phase of metamorphic competence during which, in some species, the larvae respond to stimulating physical and/or chemical cues by initiating the developmental and behavioural changes that comprise the process of metamorphosis (Doyle, 1975; Burke, 1983, 1986; Pawlik, 1992). Effective cues are generally associated with characteristics of the benthic adult habitat, including humic acids from rivers and estuaries, reduced salinities, microbial films, odors from conspecific adults, sediments, algae, or specific ions or organic chemical compounds (for recent review, see Anger, 2001; Forward et al., 2001; Gebauer et al., 2003). When effective external cues are absent, competent and receptive larvae may prolong their planktonic phase for several days or months. If such cues remain absent for longer periods, the larval phase may end with a spontaneous metamorphosis or larval death (Pechenik, 1990; Zimmerman and Pechenik, 1991; Zaslow and Benayahu, 1996; Gebauer et al., 1998).

In the present study, the period of maximum receptivity of metamorphosis-stimulating cues was experimentally investigated in the final larval stage, the megalopa, of an estuarine grapsoid crab species, Chasmagnathus granulata Dana, exposed for differential periods during the moulting cycle. This species occurs in coastal salt marshes, brackish lagoons, and other estuarine habitats in Argentina, Uruguay and southern Brazil (Boschi, 1964; Boschi et al., 1992). Its life history is characterised by an export strategy, i.e. the first larval stage leaves the brackish parental environment soon after hatching, zoeal development takes place in lower estuarine or coastal marine regions, and the megalopa returns later to recruit to the adult populations (Anger et al., 1994; Luppi et al., 2002; Giménez, 2003). The megalopa of $C$. granulata responds to cues associated with the parental habitat, in particular to muddy sediments, the presence of conspecific adults, and combinations thereof (Gebauer et al., 1998). If such cues are absent, the megalopa can postpone metamorphosis by about $2-3$ days (ca. $26-30 \%$ ), although this developmental delay also implies energetic costs that may reduce juvenile growth (Gebauer et al., 1999).

In laboratory experiments with the megalopa stage of $C$. granulata, we studied the temporal window of receptivity for previously identified external cues, addressing the 
question during which parts of the moulting cycle the larvae must be exposed to those cues to induce a measurable response in development time. This should indicate the optimal period for returning from coastal waters to estuaries, where settlement and metamorphosis are known to occur (Luppi et al., 2002).

\section{Materials and methods}

\subsection{Origin of materials, larval rearing}

Larvae of $C$. granulata were obtained from crabs originating from Mar Chiquita lagoon (Province of Buenos Aires, Argentina; see Spivak et al., 1994) and cultured since 1991 in the laboratory of the Helgoland Marine Biological Station (Germany). Our standard cultivation conditions for this species are $18{ }^{\circ} \mathrm{C}, 32 \%$ salinity and a $12: 12 \mathrm{~h} \mathrm{light/dark}$ cycle. Crabs are fed with frozen isopods (Idotea spp.), mussels (Mytilus edulis), and shrimp (Crangon crangon) from the North Sea. From hatching to the megalopa stage, the larvae were mass-reared in $10 \mathrm{~L}$ bottles with filtered (ca. $1 \mu \mathrm{m}$ ) seawater and gentle aeration, at the same constant conditions of temperature, salinity and light as the adult crabs. Water and food (freshly hatched Artemia sp., San Francisco Bay Brand) were changed daily.

\subsection{Experimental design}

In two series of experiments (A, B), each carried out with larvae from two different females (F1, F2), recently moulted megalopae (maximally $14 \mathrm{~h}$ old) were randomly assigned to various experiments with 25 individuals per treatment. In series A, the experimental exposure to metamorphosis-stimulating cues (a combination of adultconditioned seawater and fine mud; for details, see Gebauer et al., 1998, 1999) began in the various treatments on successive days after moulting to the megalopa stage (A1A11; see Fig. 1a). In series B, the megalopae were from the beginning of the experiments in contact with the stimulating cues, but the exposure was in different treatments terminated on successive days (B1-B11; Fig. 1b). In addition, each series comprised also one control group which was continually exposed (C1) and a second control (C2) which was never in contact with these cues (Fig. 1). During the change of water and food (same as for the zoeae), the megalopae were checked daily for mortality and metamorphosis. The time of development and the rate of mortality in the megalopa stage were used as quantitative criteria for possible treatment effects, i.e. of adding or withdrawing metamorphosis-stimulating cues at different times of the moulting cycle.

\subsection{Moult staging}

Megalopae sampled from parallel experiments with or without an addition of chemical cues were microscopically checked for the moulting stage using the last pair of pleopods as a reference site (classification after Drach, 1939; for details of its application to larval decapods, see Anger, 2001). 
[a] Experiment A

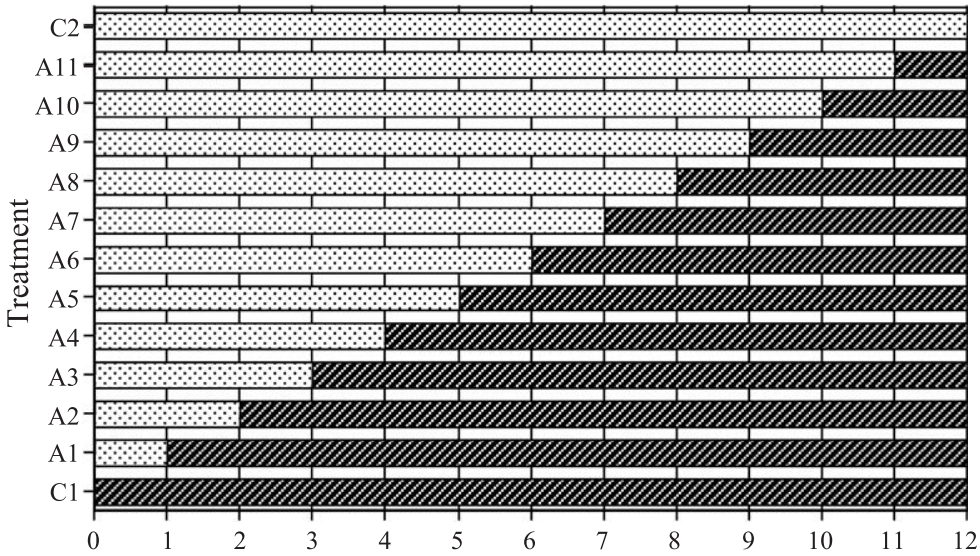

[b] Experiment B

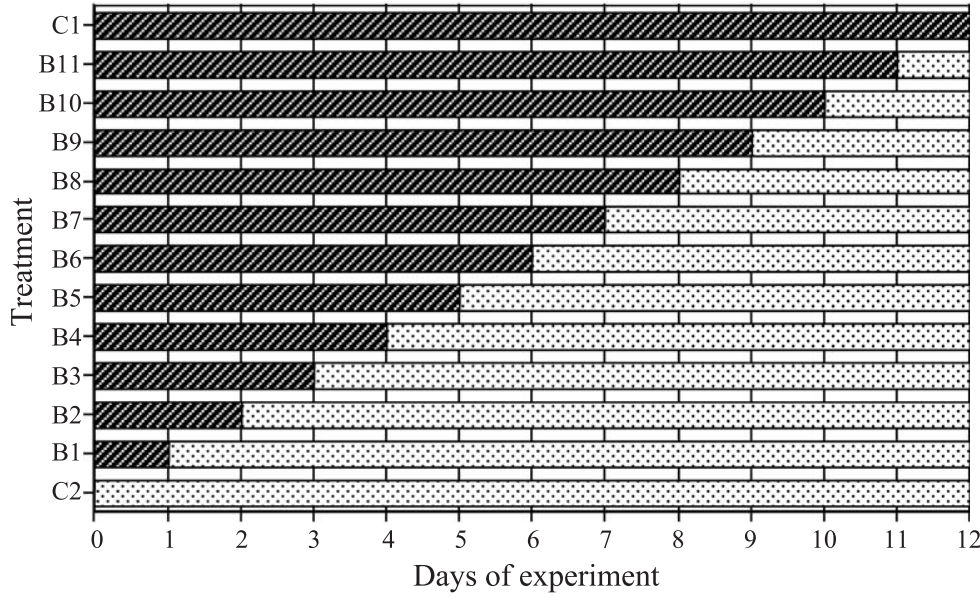

$\therefore$ days without cue $\mathbb{Z}$ days with cue

Fig. 1. Experimental design. Experiment A: A1-A11, treatments with initial absence (1-11 days) and subsequent addition of metamorphosis-stimulating cues (adult-conditioned seawater and presence of mud). Experiment B: B1-B11, treatments with initial presence (1-11 days) and subsequent withdrawal of cues. $\mathrm{C} 1$ : controls with permanent exposure to cues; $\mathrm{C} 2$ : controls with permanent absence of cues.

\subsection{Statistical methods}

Effects of the experimental treatments were tested using non parametric one-way ANOVA (Kruskal Wallis $H$-tests), as some data did not comply with the prerequisites of normality and homogeneity of variance (Kolmogorov-Smirnov and Levene test, respectively). Multiple comparisons with the control groups $(\mathrm{C} 1, \mathrm{C} 2)$ were done using Dunn's test for data sets with different size and non-normal distribution. An $\mathrm{R} \times \mathrm{C}$ test of independence was used to analyze effects of treatments on mortality (Sokal and Rohlf, 
1995). Average values are given as arithmetic mean \pm one standard deviation (SD). A sigmoidal and exponential decay curve was fitted to data of developmental delay using the least-squares method.

\section{Results}

The survival of megalopae through metamorphosis varied in the two experimental series from $44 \%$ to $100 \%$. In larvae obtained from $\mathrm{F} 1$ but not in those from F2, an $\mathrm{R} \times \mathrm{C}$ test of independence indicated in experiment $\mathrm{A}$ a statistically significant variation of mortality rates $(G=34.1 ; P<0.05)$. This was caused by an exceptionally high mortality occurring exclusively in treatment A10 (56\% vs. $4-20 \%$ in all other treatments and controls). However, no relationship of the mortality pattern with the timing or duration of exposure to metamorphosis-stimulating cues could be recognized. In the treatments and controls of experiment B, no significant variation was detected in the mortality rates of megalopae originating from either F1 or F2.

The duration of development to metamorphosis showed highly significant effects of the timing or duration of exposure to stimulating cues. The development duration of megalopae exposed continuously (control $\mathrm{C} 1$ ) did not vary significantly between the two hatches tested (larvae from females F1, F2), with $9.3 \pm 0.6$ and $9.6 \pm 1.0$ days, respectively ( $U$-test, $P>0.6$ ). In the control without any exposure to those cues $(\mathrm{C} 2)$, by contrast, the average time of megalopa development was significantly shorter in F1 individuals than in those originating from F2 (U-test, $P<0.02$ ), with $11.2 \pm 1.2$ and $12.4 \pm 1.3$ days, respectively, and both differed significantly from the corresponding $\mathrm{C} 1$ controls $(U$-test, $P<0.0001)$. Because of significant differences in the time of development of F1 and F2 megalopae, the data obtained from the two different females were analyzed separately.

\subsection{Experiment $A$}

In experiment $\mathrm{A}$, the timing of the addition of the stimulating chemical cue had a significant effect on the duration of development through the megalopa stage in larvae from both females (Fig. 2; $H$-test, $P<0.0001$ ). Through multiple comparison analysis (Dunn's tests), two groups could be identified. The first one comprised the control C1 as well as treatments $\mathrm{A} 1-\mathrm{A} 2$ (in F1 larvae) or A1-A3 (in F2; unshaded columns in Fig. 2), with average stage durations ranging between $9.3 \pm 0.6$ and $10.2 \pm 1.0$. This indicates that development duration in treatments with an early exposure to adult-conditioned water and mud (beginning 2-3 days after moulting to the mealopa stage) did not significantly differ from that observed in the continuously exposed control (C1).

The second group comprised all treatments with later beginning of the exposure to the cues (A3-A11 or A4-A11 in F1 and F2, respectively; shaded columns in Fig. 2). In this group, the average time of development to metamorphosis $(11.0 \pm 1.0$ and $12.4 \pm 1.3$ days) was significantly delayed compared to the $\mathrm{C} 1$ control, while no significant differences were found to the continuously unexposed control (C2). These results indicate that the signal from the cues had to appear within about 2-3 days of the moulting cycle to 

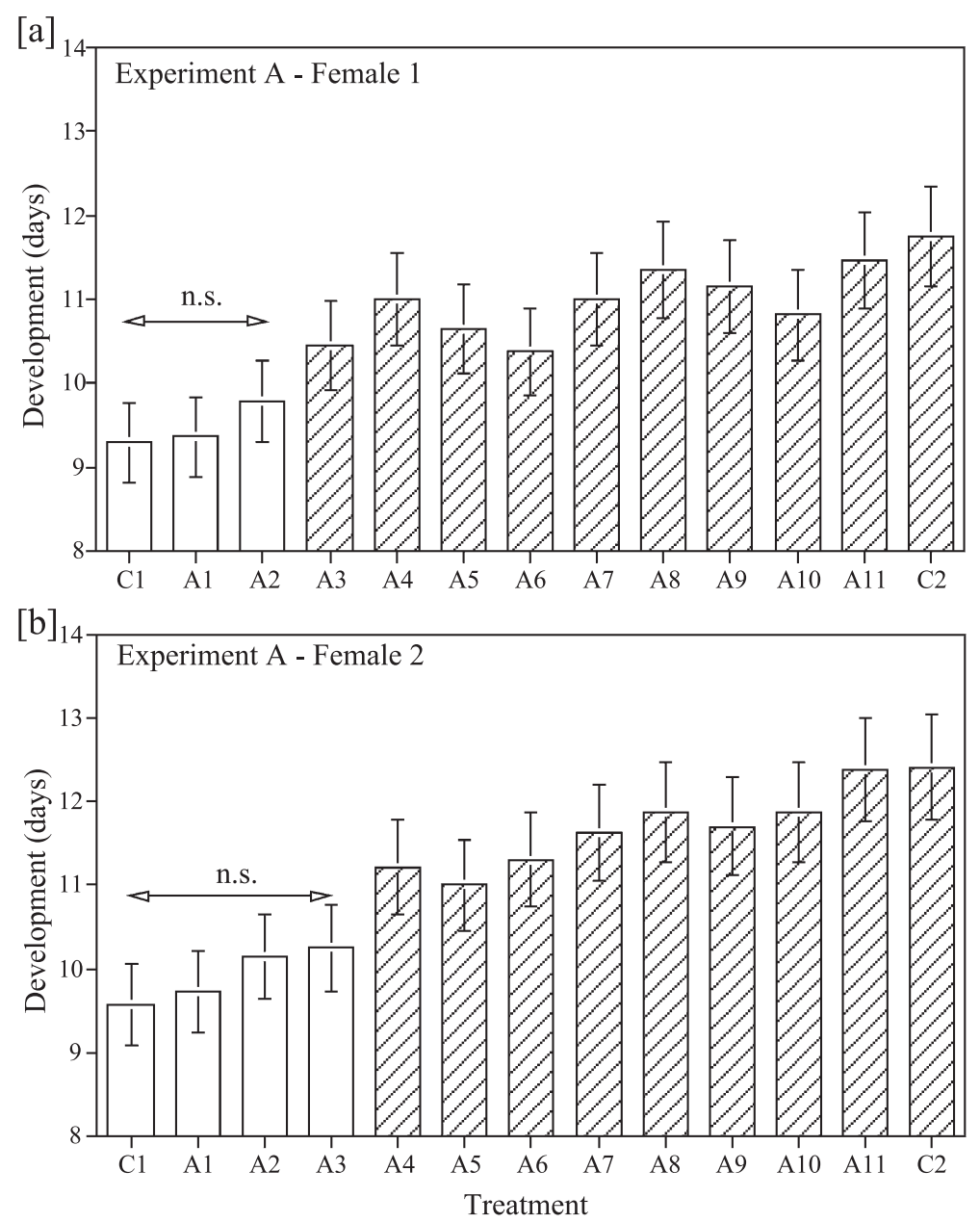

Fig. 2. Experiment A. Development time of megalopae to metamorphosis (days, mean $\pm \mathrm{SD}$ ); materials originating from two different females, exposed for differential periods to metamorphosis-stimulating cues (for treatments, see Fig. 1); n.s.: treatments where development time was not significantly different from that in the permanently exposed control group, $\mathrm{C} 1$ (Kruskal-Wallis $H$ tests; white columns); shaded columns: treatments with significant developmental delay compared to $\mathrm{C} 1(P<0.05)$.

become effective. Later beginning of the exposure had no more significant stimulating effect, even if it lasted throughout the remaining period of the moulting cycle (comprising up to more than $70 \%$ of total time).

\subsection{Experiment $B$}

In series $\mathrm{B}$ experiments conducted with larvae from female F2, all megalopae in treatment B11 metamorphosed before the cue was removed. As a consequence, this 
treatment became a continuously exposed control experiment $(\mathrm{C} 1)$, and the total number of treatments was, in this exceptional case, reduced to ten (see Figs. 2b and 3b).

In larvae from F1, two groups were statistically separated, as in experiment A. One group (white columns in Fig. 3) comprised the permanently exposed control $\mathrm{C} 1$ as well as treatments with an initial exposure for at least 4 or 6 days (megalopae originating from $\mathrm{F} 1$ or F2, respectively) followed by rearing in seawater without the cue (treatments B4-B11 or B6-B10 in F1 and F2, respectively). The average time of development ranged, in this group, from $9.3 \pm 0.5$ to $10.1 \pm 1.0$ days (F1 and F2, respectively). The second group
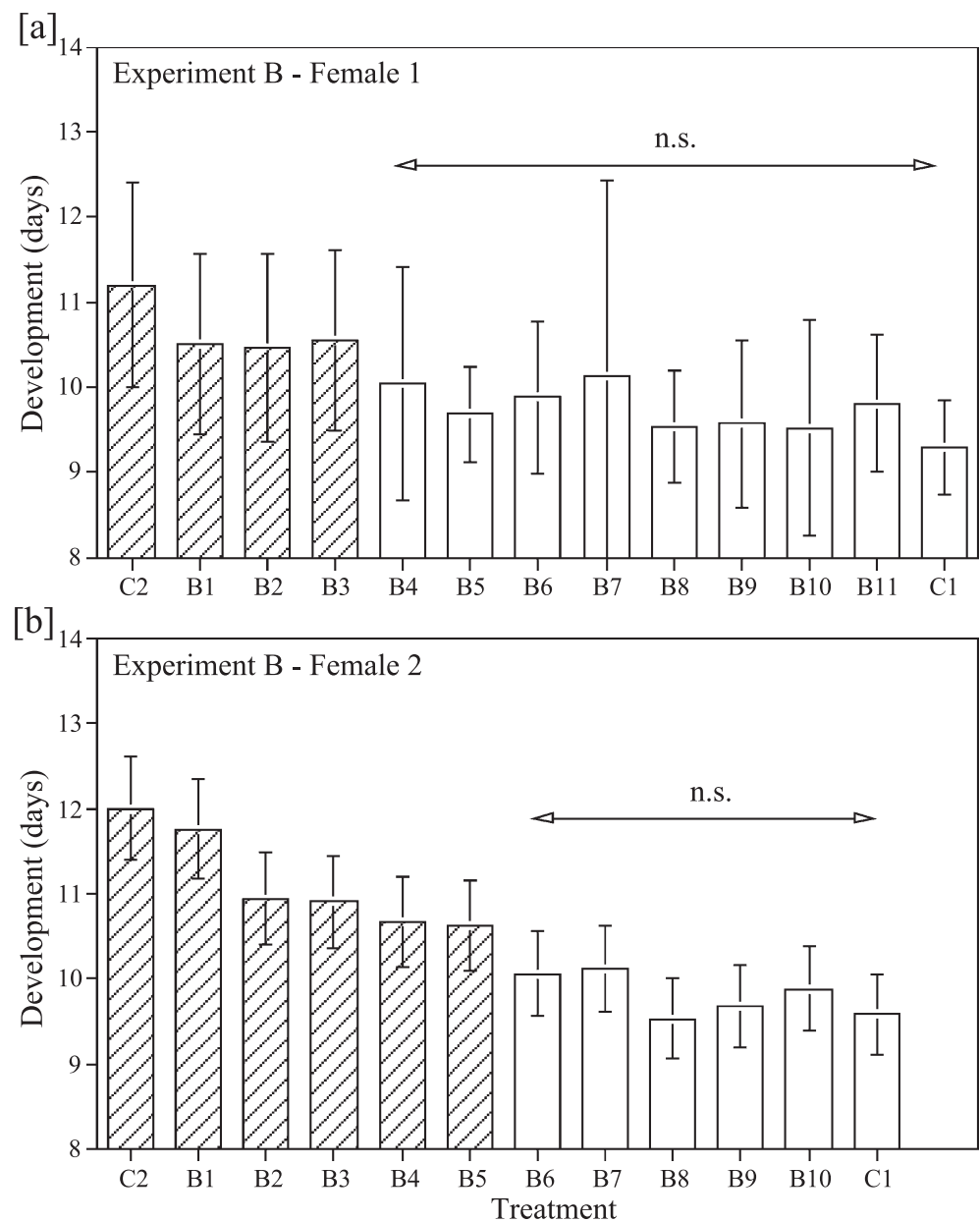

Fig. 3. Experiment B. Development time of megalopae to metamorphosis (days, mean \pm SD); materials originating from two different females, exposed for differential periods to metamorphosis-stimulating cues (for treatments, see Fig. 1); n.s.: treatments where development time was not significantly different from that in the permanently exposed control group, $\mathrm{C} 1$ (Kruskal-Wallis $H$ tests; white columns); shaded columns: treatments with significant developmental delay compared to $\mathrm{C} 1(P<0.05)$. 
(shaded columns in Fig. 3) consists of treatments where the time of the initial contact with the cue was shorter (B1-B3 or B1-B5 in F1 and F2 megalopae, respectively). These treatments, with mean moult-cycle durations ranging between $10.5 \pm 1.1$ and $11.2 \pm 1.2$ days (F1) or between $10.6 \pm 1.2$ and $12.0 \pm 1.3$ days (F2), showed a significant developmental delay compared to the control $\mathrm{C} 1$. In the development time of larvae obtained from F1, none of these treatments differed significantly from the completely

[a] Initial days with cue

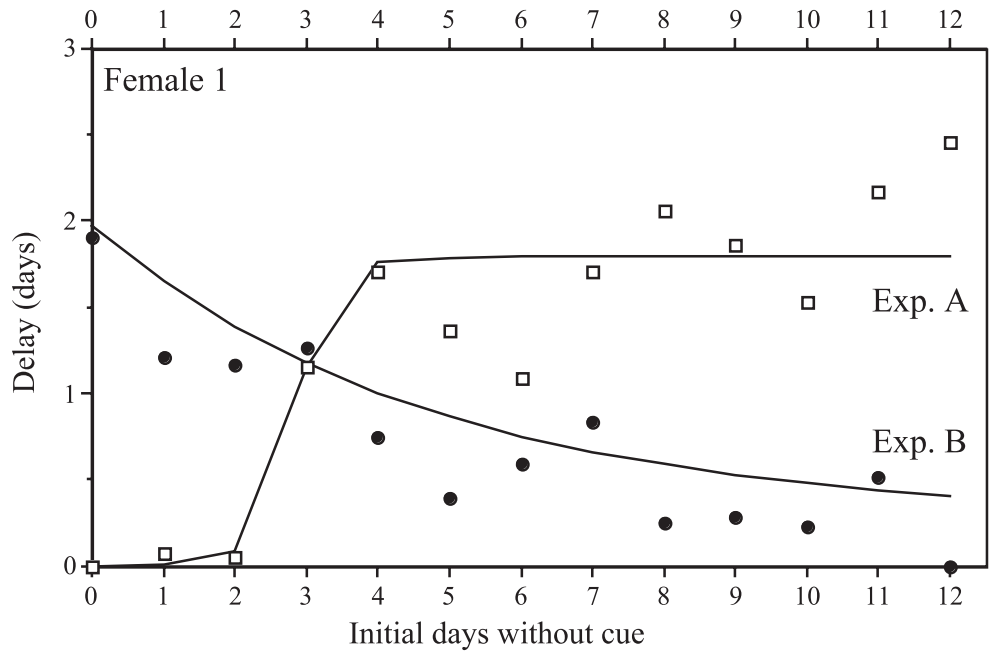

[b]

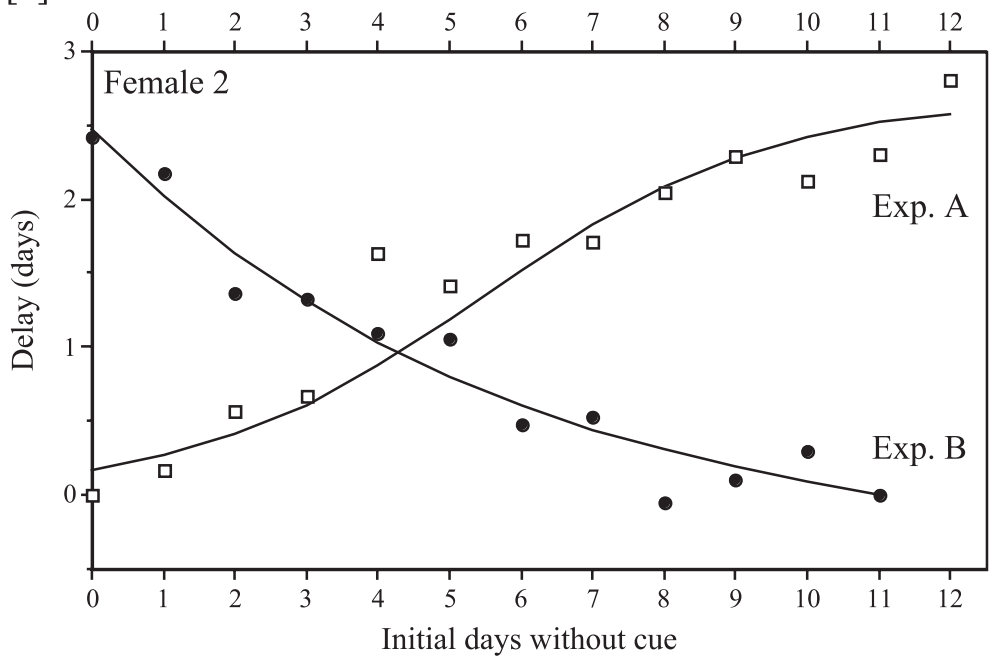

Fig. 4. Comparison of developmental delay (days) in experiments A and B (cf. Fig. 1); materials originating from two different females. 
unexposed control, C2. In experiments with F2 megalopae, however, a third group was statistically identified: Treatments B4 and B5 showed an intermediate response level with a significant developmental delay compared to $\mathrm{C} 1$ but also a significantly shorter development time compared to $\mathrm{C} 2$.

The maximum delay was thus $2.5-2.8$ days (F1, F2, respectively), corresponding to $26-30 \%$ of the average duration of megalopa development in the $\mathrm{C} 1$ control. When the average duration of the delay, $y$, in a treatment was related to the initial time without cues, $x$, in Experiment A, a significant sigmoidal relationship was observed (Fig. 4; $P<0.05$ ), which can be described with the following fitted equations for F1 (with $r^{2}=0.83$ ) and F2 $\left(r^{2}=0.95\right)$, respectively:

$$
\begin{aligned}
& y=1.79 /\left[1+\mathrm{e}^{(2.84-x) / 0.27}\right] \\
& y=2.68 /\left[1+\mathrm{e}^{(5.47-x) / 2.01}\right]
\end{aligned}
$$

When the time of metamorphic delay, $y$, was related to the initial period of exposure to the cue, $x$, in Experiment B, an exponential decay model showed consistently a non-linear decrease with increasing time of initial exposure (Fig $4 ; P<0.05 ; r^{2}=0.85$ and $r^{2}=0.95$ in F1 and F2, respectively):

$$
\begin{aligned}
& y=1.70 \cdot \mathrm{e}^{(-0.21 \cdot x)}+0.08 \\
& y=2.92 \cdot \mathrm{e}^{(-0.17 \cdot x)}-0.46 .
\end{aligned}
$$

\section{Discussion}

Metamorphosis from the megalopa to the first benthic juvenile stage of a highly gregarious salt marsh crab, $C$. granulata, is triggered by chemical cues that are associated with the adult habitat, in particular by presence of mud and/or odors from conspecific adults (Gebauer et al., 1998). Adult odors may also stimulate metamorphosis in related species, although the effectiveness appears to decrease with increasing phylogenetic distance (Gebauer et al., 2002). Lack of exogenous cues causes a developmental delay which is generally short (maximally about $30 \%$ ), but probably sufficient to enhance the chance of finding a more suitable benthic habitat for settlement. While this response should reduce postsettlement mortality and may thus be considered as adaptive, delayed metamorphosis implies also tradeoffs (see Pechenik, 1990; Pechenik et al., 1998). In C. granulata, this is associated with a reduction of early juvenile body size and, as a presumable consequence, reduced competetive fitness of juvenile crabs (Gebauer et al., 1999).

The results of our present study show that the timing and duration of exposure to chemical cues within the megalopal moulting cycle represent further critical factors. Similar observations suggesting a particular temporal window of receptiveness were also 
reported for megalopae of a gregarious fiddler crab, Uca pugnax (O'Connor and Gregg, 1998). In C. granulata, an initial exposure during the postmoult phase (moult cycle classification system: Drach, 1939; Skinner, 1962; Drach and Tchernigovtzeff, 1967) had a stimulating effect only if it lasted at least for about one third to one half of total moultcycle duration (experiment B, see Fig. 3). In treatments where cues were initially absent during the postmoult phase (experiment A, Fig. 2), the signal had to appear no later than after about $20-30 \%$ of the average development time through the megalopa stage to trigger metamorphosis. Later appearance of those cues, by contrast, had no more stimulating effect, even if the subsequent exposure was extended throughout the remaining time of the moulting cycle, i.e. through the entire premoult period, $\mathrm{D}_{0}-\mathrm{D}_{4}$ (see treatments A3 or A4 to A11; Fig. 2).

As an overall conclusion from both series of experiments (see Fig. 4), stimulating effects were consistently observed during a period ranging from about $20-50 \%$ of the moulting cycle, while earlier or later exposure had little or no effect. This period may thus represent the temporal window of maximum responsiveness or receptivity for metamorphosis-stimulating cues.

As ascertained by microscopical inspection of megalopae, and in agreement with the literature (see Anger, 2001), this receptive period coincides approximately with the duration of the intermoult stage (C) of Drach's system. Treatments with complete absence of cues during this period within the moulting cycle, with too short duration of exposure, or with too early withdrawal or too late appearance of the cue (restricted to postmoult, stages $\mathrm{A}-\mathrm{B}$, or premoult, $\mathrm{D}_{0}-\mathrm{D}_{4}$ ) caused a significant lengthening of the moulting cycle. This suggests that the typical events of early premoult $\left(\right.$ stage $\left.\mathrm{D}_{0}\right)$, which comprise an increase in the titer of moulting hormones, the detachment of the epidermis from the old cuticle (apolysis), and other hormonal and morphogenetic changes, may be accelerated by previous exposure to a stimulating chemical cue. Since $\mathrm{D}_{0}$ is critical also in relation to larval starvation resistance and, possibly, other stress factors (Anger, 2001), this point in megalopa development may be critical also for the effectiveness of metamorphosis-stimulating cues. This suggests that the mode of action of extrinsic cues interact with intrinsic (hormonal) factors controlling the course of the moulting cycle, including the antagonistic system of ecdysteroids released from the Y-organs and neuropeptides from the X-organ-sinus gland complex (see Chang, 1995; Charmantier and Charmantier-Daures, 1998).

When development duration is compared between megalopae produced by different females, no significant difference was observed in controls or treatments with effective stimulation by chemical cues. However, the developmental delay in experiments with absent or insufficient stimulation varied significantly between the two hatches used in the present study, as well as between the present data and previously observed development times (cf. Gebauer et al., 1998). This indicates that genetical and/or maternal factors are also involved in the control of metamorphosis. Among those potentially confounding factors, individual variability in the initial egg size of $C$. granulata has been shown to affect larval biomass at hatching, this has consequences for the course and average duration of larval development to metamorphosis (including the number of zoeal stages), and all this may eventually influence the postmetamorphic size and growth of early benthic juveniles (Giménez et al., 2004). Such complex relationships between traits in different life-history phases show that intraspecific variability should receive more attention in future research. 
If intraspecific genetic variability is significant, the responsiveness to chemical cues should be subject to variable selection pressure under different habitat conditions. When, for instance, suitable substrates (e.g. soft sediments allowing for tube building) are very patchy or rare, this should select for morphs with a strong delaying response to the absence of cues. On the other hand, strong benthic predation pressure or competition in densely populated habitats (see Luppi et al., 2002) may favour the success of less responsive morphs producing larger juveniles, which should then be stronger in biotic interactions (Gebauer et al., 2003).

Future investigations will chemically identify and further elucidate the effects of metamorphosis-stimulating cues in decapod crustaceans and other marine invertebrates. Furthermore, the adaptive value of delayed metamorphosis under various scenarios of selection pressures, the genetical basis of variable responsiveness among hatches or populations, as well as implications for life-history evolution should be addressed.

\section{Acknowledgements}

The first author acknowledges a grant from the Biologische Anstalt Helgoland and the Dirección de Investigación y Desarrollo (project DID D2001-12-Universidad Austral de Chile). The second author was funded by Deutscher Akademischer Austauschdienst (DAAD; Bonn, Germany), the Universidad Austral de Chile (MECESUP AUS-9908), and the Dirección de Investigación y Desarrollo (project DID S200159-Universidad Austral de Chile). [SS]

\section{References}

Anger, K., 2001. The Biology of Decapod Crustacean Larvae. Crustacean Issues 14. A.A. Balkema Publishers, Swets and Zeitlinger, Lisse, ISSN 0168-6456, pp. 1-420.

Anger, K., Spivak, E., Bas, C., Ismael, D., Luppi, T., 1994. Hatching rhythms and dispersion of decapod crustacean larvae in a brackish coastal lagoon in Argentina. Helgol. Meeresunters. 48, 445-466.

Boschi, E.E., 1964. Los crustáceos decápodos Brachyura del litoral bonaerense (R. Argentina). Boln. Inst. Biol. Mar del Plata 6, 1-100.

Boschi, E.E., Fischbach, C.E., Iorio, M.I., 1992. Catálago ilustrado de los crustáceos estomatópodos y decápodos marinos de Argentina. Frente Marít., Uruguay 10, 7-94.

Burke, R.D., 1983. The induction of metamorphosis of marine invertebrate larvae: stimulus and response. Can. J. Zool. 61, 1701-1719.

Burke, R.D., 1986. Pheromones and the gregarious settlement of marine invertebrate larvae. Bull. Mar. Sci. 39, $323-331$.

Chang, E.S., 1995. Physiological and biochemical changes during the molt cycle in decapod crustaceans: an overview. J. Exp. Mar. Biol. Ecol. 193, 1-14.

Charmantier, G., Charmantier-Daures, M., 1998. Endocrine and neuroendocrine regulations in embryos and larvae of crustaceans. Inv. Reprod. Dev. 33, 273-287.

Doyle, R., 1975. Settlement of planktonic larvae: a theory of habitat selection in varying environments. Am. Nat. $109,113-126$.

Drach, P., 1939. Mue et cycle d'intermue chez les Crustacés Décapodes. Ann. Inst. Océanogr., Monaco 19, $103-391$.

Drach, P., Tchernigovtzeff, C., 1967. Sur la méthode de détermination des stades d'intermue et son application générale aux crustacés. Vie Milieu, Sér. A Biolog. Mar. 18, 595-609. 
Forward, R.B., Tankersley, R.A., Rittschof, D., 2001. Cues for metamorphosis of brachyuran crabs: an overview. Am. Zool. 41, 1108-1122.

Gebauer, P., Walter, I., Anger, K., 1998. Effects of substratum and conspecific adults on the metamorphosis of Chasmagnathus granulata (Dana) (Decapoda: Grapsidae) megalopae. J. Exp. Mar. Biol. Ecol. 223, 185 - 198.

Gebauer, P., Paschke, K., Anger, K., 1999. Costs of delayed metamorphosis: reduced growth and survival in early juveniles of an estuarine grapsid crab, Chasmagnathus granulata. J. Exp. Mar. Biol. Ecol. 238, $271-281$.

Gebauer, P., Paschke, K., Anger, K., 2002. Metamorphosis in a semiterrestrial crab, Sesarma curacaoense: intra and interspecific settlement cues from adult odors. J. Exp. Mar. Biol. Ecol. 268, 1-12.

Gebauer, P., Paschke, K., Anger, K., 2003. Delayed metamorphosis in decapod crustaceans: evidence and consequences. Rev. Chil. Hist. Nat. 76, 169-175.

Giménez, L., 2003. Potential effects of physiological plastic responses to salinity on population networks of the estuarine crab Chasmagnathus granulata. Helgol. Mar. Res. 56, 265-273.

Giménez, L., Torres, G., Anger, K., 2004. Linking life history traits in successive phases of a complex life cyle: effects of larval biomass on early juvenile development in an estuarine crab, Chasmagnathus granulata. Oikos 104, 570-580.

Luppi, T.A., Spivak, E.D., Anger, K., Valero, J.L., 2002. Patterns and processes of Chasmagnathus granulata and Cyrtograpsus angulatus (Brachyura: Grapsidae) recruitment in Mar Chiquita Coastal Lagoon, Argentina. Estuar. Coast. Shelf Sci. 55, 287-297.

O'Connor, N.J., Gregg, A.S., 1998. Influence of potential habitat cues on duration of the megalopal stage of the fiddler crab Uca pugnax. J. Crustac. Biol. 18, 700-709.

Pawlik, J.R., 1992. Chemical ecology of the settlement of benthic marine invertebrates. Oceanogr. Mar. Biol. Annu. Rev. 30, 273-335.

Pechenik, J.A., 1990. Delayed metamorphosis by larvae of benthic marine invertebrates: does it occur? Is there a price to pay? Ophelia 32, 63-94.

Pechenik, J.A., Wendt, D.E., Jarrett, J.N., 1998. Metamorphosis is not a new beginning. Bioscience 48, $901-910$.

Skinner, D.M., 1962. The structure and metabolism of a crustacean integumentary tissue during a molt cycle. Biol. Bull. 123, 635-647.

Sokal, R.R., Rohlf, F.J., 1995. Biometry. The Principles and Practices of Statistics in Biological Research, 3rd ed. Freeman, New York.

Spivak, E., Anger, K., Luppi, T., Bas, C., Ismael, D., 1994. Distribution and habitat preferences of two grapsid crab species in Mar Chiquita Lagoon (Province of Buenos Aires Argentina). Helgol. Meeresunters. 48, 59-78.

Thorson, G., 1950. Reproduction and larval ecology of marine bottom invertebrates. Biol. Rev. 25, 1-45.

Zaslow, R.B.D., Benayahu, Y., 1996. Longevity, competence and energetic content in planulae of the soft coral Heteroxenia fuscescens. J. Exp. Mar. Biol. Ecol. 206, 55-68.

Zimmerman, K.M., Pechenik, J.A., 1991. How do temperature and salinity affect relative rates of growth, morphological differentiation, and time to metamorphic competence in larvae of the marine gastropod Crepidula plana? Biol. Bull. 180, 372-386. 